\title{
Infrared Spectra Patterns of Coconut Shell Charcoal as Result of Pyrolysis and Acid Activation Origin of Sulawesi, Indonesia
}

\author{
Meytij Jeanne Rampe ${ }^{1 *}$, Ignatius R. S. Santoso ${ }^{1}$, Henny Lieke Rampe ${ }^{2}$, Vistarani Arini Tiwow ${ }^{3}$, Anastasya Apita $^{1}$ \\ ${ }^{1}$ Manado State University, Indonesia. \\ ${ }^{2}$ Sam Ratulangi University, Indonesia. \\ ${ }^{3}$ Makassar State University, Indonesia.
}

\begin{abstract}
Coconut is one of the industrial plants that plays an important role in the Indonesian economy. The part of coconut that has a high economic value is the coconut shell. This study aims to see the maximum temperature of the coconut shell pyrolysis reactor and to examine the spectrum pattern of charcoal purified using the activation of hydrochloric acid $(\mathrm{HCl})$, acetic acid $\left(\mathrm{CH}_{3} \mathrm{COOH}\right)$, nitric acid $\left(\mathrm{HNO}_{3}\right)$ and hot water $\left(\mathrm{H}_{2} \mathrm{O}\right)$. The process steps are pyrolysis process carried out at a temperature of $\pm 310{ }^{\circ} \mathrm{C}$ for 2 hours and activation using 4 types of solvents with different acidity levels, soaking for 12 hours. Infrared spectra pattern testing using Fourier Transform Infrared (FTIR). The results of the pyrolysis process produce charcoal, liquid smoke, tar and condensed gases. The spectral pattern of each purified charcoal was analyzed using Fourier Transform Infrared (FTIR). The results of the analysis showed that the spectral pattern of activated charcoal showed a spectral pattern with a low level of impurity absorption, namely the spectral pattern of charcoal using $\mathrm{HCl}$ activator at a concentration of $2 \mathrm{M}$.
\end{abstract}

Keywords: Spectra pattern, coconut shell charcoal, activation, FTIR

\section{Introduction}

In North Sulawesi, especially in Kauditan Village, North Minahasa Regency, coconut shells produced from copra farmers are only used as fuel in the process of processing coconuts into copra, as well as fuel for grilling fish or other food ingredients, in fact there are still many people who sell coconut shells at low prices. which is relatively cheap, whereas if the coconut shell is further processed it will create added value from the coconut commodity. One of the processed coconut shell products that have prospects is charcoal which is a raw material in making briquettes which in the next process can be processed as activated carbon.

Coconut shell is good for charcoal because it has good hardness, high levels of bound carbon and low mineral ash content. When coconut shell is pyrolyzed, the main product is charcoal with volatile components, water and ash as a by-product. Charcoal components consist of bound carbon, ash, water, nitrogen, and sulfur. Most of the charcoal pores are still covered with hydrocarbons, tar, and other organic compounds also still contain inorganic elements, namely magnesium $(\mathrm{Mg})$, Aluminum (A1), Potassium (K), Calcium (Ca), Iron $(\mathrm{Fe})[1]$.

Charcoal can be made by direct or indirect heating in heaps or kilns in this decomposition process in addition to charcoal, other products such as distillates and gas can be produced [2]. The process of heating the coconut shell will produce gradual changes. The first stage is known as carbonization, the carbon sample becomes coke, the second is known as the graphitization stage, which is changing the coke into graphite so that carbon with an irregular structure develops a graphite collar with a regular structure.

Coconut shell charcoal can be processed into commodities that have considerable added value, namely into activated carbon. Activated carbon has many benefits, one of which is as an absorbent of impurities, also in the pharmaceutical or drug industry, namely norit or better known as stomach aches, it is activated carbon made from coconut shell charcoal. It is estimated that in the future the demand for activated carbon made from charcoal from coconut shells will increase [3].

Charcoal purification is carried out to obtain pure charcoal that is free from inorganic compounds which will later be used as raw materials in various products, usually using acid compounds that aim to remove metals bound to the charcoal. As has been done by [4] to get pure charcoal that is free from organic minerals, the charcoal is soaked using hydrochloric acid solvent for 24 hours. In this study, four types of solvents were used, namely hydrochloric acid, acetic acid, nitric acid and hot

\footnotetext{
* Corresponding author : meytijrampe@unima.ac.id
} 
water. Acid solvents will more easily dissolve alkaline impurities so that they will form inorganic salts, while hot water is used to dissolve organic compounds [5].

The purified charcoal was then analyzed using the Fourier Transform Infra red (FTIR) analysis method. This FTIR absorption analysis was used to determine the functional groups contained in the sample. FTIR spectroscopy is infrared spectroscopy equipped with Fourier transform to detect and analyze the spectrum results. The infrared spectrum obtained is then plotted as a function of energy intensity, wavelength $(\mu \mathrm{m})$ or wave number $\left(\mathrm{cm}^{-1}\right)$. Analysis of the functional groups of a sample is carried out by comparing the absorption bands formed in the infrared spectrum using a correlation table and using the spectrum of the comparison compound (which is already known).

\section{Research Methods}

\subsection{Research Tools and Materials}

The tools used are pyrolysis reactor, FTIR Shimadzu prestige-21, mortar and pestle, pipette, 40 mesh sieve, porcelain cup and glassware commonly used in the laboratory.

The materials used were coconut shell from Kauditan Village, Kauditan District, North Minahasa Regency, hydrochloric acid, (pa brand), acetic acid (pa brand), nitric acid (pa brand), aluminum foil, universal $\mathrm{pH}$, Whatman filter paper no 42 .

\subsection{Data Collection and Analysis Techniques}

The sample used was a random $2 \mathrm{~kg}$ coconut shell, cleaned of coir and dirt that was still attached to the shell using a knife, then dried by drying in the sun. Furthermore, the coconut shell is made into smaller pieces by pounding it with a hammer.

Coconut shell pieces are put into the pyrolysis reactor, the lid of the furnace is tightly closed so that no oxygen enters during the heating process. Coconut shell was pyrolyzed at $\pm 310^{\circ} \mathrm{C}$ for 2 hours, then coconut shell charcoal was obtained. The coconut shell charcoal resulting from pyrolysis is cleaned from the attached coir charcoal using a knife, then the charcoal is mashed into powder by pounding it using a porcelain mortar. The charcoal powder was then sieved with a 40 mesh sieve to uniform the particle size so that carbon powder with a particle size passed through a 40 mesh sieve [2].

5 grams of charcoal powder soaked with hydrochloric acid (1 $\mathrm{M}$ and $2 \mathrm{M}$ ), acetic acid (1 M, 2M) nitric acid $(1 \mathrm{M}, 2 \mathrm{M})$ with a volume ratio of $5: 20 \mathrm{~g} / \mathrm{ml}$ and hot water $\pm 90 \mathrm{oC}$, soaked for 24 hours. The soaked charcoal was filtered through Whatman No. filter paper. 42 , then washed with distilled water until the washing water shows a neutral $\mathrm{pH}(\mathrm{pH}$ 7). The purified charcoal powder is dried in an oven at a temperature of $120 \mathrm{oC}$ for 12 hours [4].

The purified coconut shell charcoal powder was analyzed using Shimadu's Fourier Transform Infrared (FTIR) analysis of the Prestige 21 model, the $\mathrm{KBr}$ pellet method, in the Laboratory of Organic Chemistry, Gajah Mada University, Yokyakarta, Indonesia.

\section{Results and Discussion}

The coconut shells used in this study came from Kauditan Village, Kauditan District, North Minahasa Regency, North Sulawesi, which is the residue of making copra from people's plantations. The coconut shell sample is shown in Figure 1.
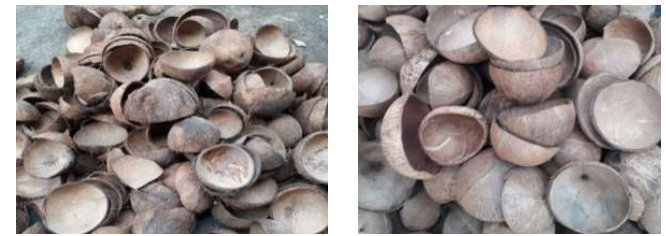

Fig. 1. Coconut Shell

Coconut shell pyrolysis process using a pyrolysis reactor at a temperature of $\pm 310^{\circ} \mathrm{C}$ for 2 hours.

The pyrolysis process is carried out to produce coconut shells, some of which become charcoal and some are not. There are three components resulting from the pyrolysis of coconut shells, namely $350 \mathrm{ml}$ of liquid smoke, 950 grams of fine charcoal and $10 \mathrm{ml}$ of tar. Coconut shell charcoal chips resulting from pyrolysis at a temperature of $\pm 300{ }^{\circ} \mathrm{C}$ and charcoal powder are shown in Figure 2 ( $a$ and $b$ ).
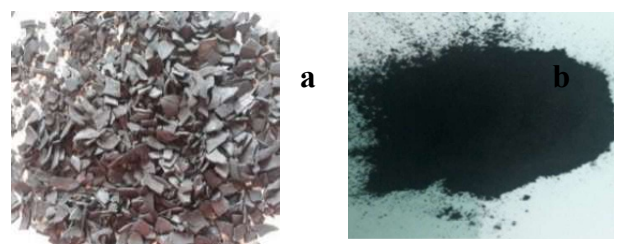

Fig.2. Coconut shell charcoal: Charcoal chips (a), Charcoal powder (b)

Functional groups of charcoal resulting from coconut shell pyrolysis using a Shimadu FTIR spectrometer model IR-Prestige 21, with a wave number of 500 to $4000 \mathrm{~cm}^{-1}$.

The pattern of FTIR spectra of charcoal from the activation of hydrochloric acid $(\mathrm{HCl} 1 \mathrm{M}$ and $2 \mathrm{M})$ is shown in Figure 3.

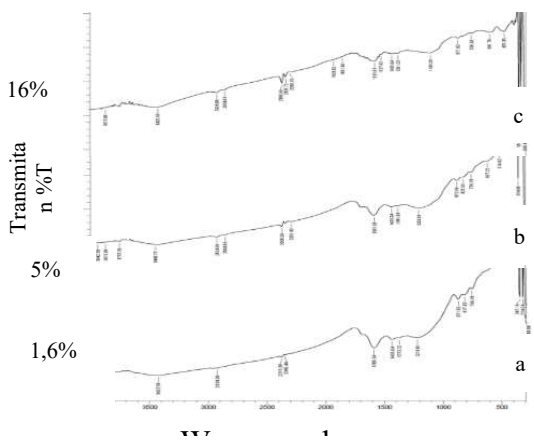

Fig.3. FTIR spectrum spectra (a) Basic material charcoal (b) Charcoal purified with $1 \mathrm{M} \mathrm{HCl} \mathrm{(c)}$ Charcoal purified with $2 \mathrm{M} \mathrm{HCl}$ 
Showing the lost absorption and decreasing the intensity of the absorption that occurs indicates the reduction of impurities in the charcoal, this indicates that there will be the formation of aromatic compounds which are the constituents of the hexagonal crystallite structure of the charcoal. Activation with $2 \mathrm{M} \mathrm{HCl}$ Concentration.

The absorption appears at a wave number of around $3400 \mathrm{~cm}^{-1}$ which indicates the presence of an $\mathrm{OH}$ group, the absorption that appears at a wave number of 2900 $2800 \mathrm{~cm}^{-1}$ indicates the presence of an aliphatic $\mathrm{CH}$ group, the absorption at a wavelength of $2300-1800 \mathrm{~cm}^{-}$ 1 indicates the presence of a $\mathrm{C}=\mathrm{O}$ group which is a carbonyl group. Absorption at wave number 1500-1400 $\mathrm{cm}^{-1}$ indicates the presence of aromatic $\mathrm{C}=\mathrm{C}$ which is a hexagonal form of charcoal, absorption at wave number $1300-800 \mathrm{~cm}^{-1}$ indicates the presence of a CO group, then absorption at wave number $700-400 \mathrm{~cm}^{-1}$ indicates the presence of the aromatic $\mathrm{CH}$ group of the hydrocarbon $[2,4]$.

The spectrum of the Fourier Transform Infra Red (FTIR) analysis of the activated charcoal using acetic acid $\left(\mathrm{CH}_{3} \mathrm{COOH}\right)$ shown in (Figure 4$)$ basically gives almost the same absorption band peaks.

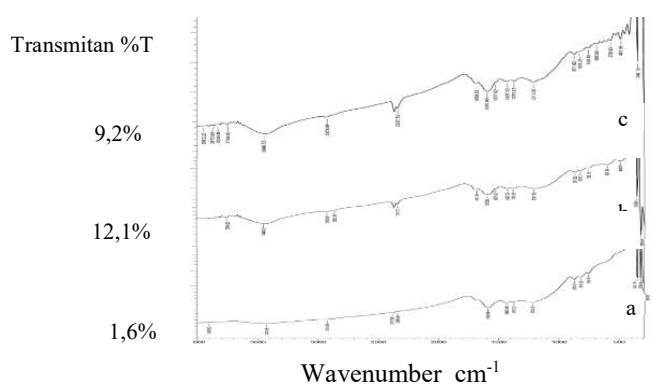

Fig.4. FTIR Spectrum (a) Base material charcoal (b) 1 $\mathrm{M} \mathrm{CH}_{3} \mathrm{COOH}$ activated charcoal (c) $2 \mathrm{M} \mathrm{CH} 3 \mathrm{COOH}$ activated charcoal

With the loss of absorption and the decrease in the intensity of the absorption that occurs, it shows a decrease in impurities in the charcoal, this indicates that there will be the formation of aromatic compounds which are the constituents of the hexagonal crystallite structure of charcoal. And it is shown by the charcoal soaked with acetic acid concentration of $1 \mathrm{M}$.

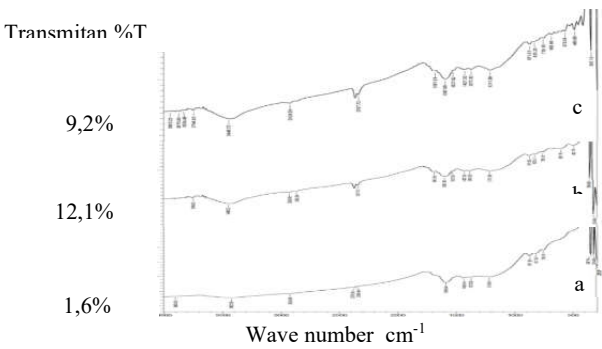

Fig. 5. FTIR Spectrum (a) Basic material charcoal (b) 1 $\mathrm{M} \mathrm{CH} 3 \mathrm{COOH}$ activated charcoal (c) $2 \mathrm{M} \mathrm{CH} 3 \mathrm{COOH}$ activatied charcoal.
The absorption band peak that appears continuously at a wave number of $3448.72 \mathrm{~cm}-1$ which indicates the presence of an $\mathrm{OH}$ group. The wave number with an absorption band peak of $2924.09-2862,36 \mathrm{~cm}^{-1}$ indicates the vibration of the aliphatic $\mathrm{C}-\mathrm{H}$ group which indicates a hydrocarbon compound. The wave number with the absorption band peak appearing at wave number $2337.72 \mathrm{~cm}^{-1}$ indicates the vibration of the $\mathrm{C}=\mathrm{O}$ group. Wave number $1681.93 \mathrm{~cm}-1-1427.32 \mathrm{~cm}^{-1}$ indicates the vibration of the aromatic $\mathrm{C}=\mathrm{C}$ group. The wave number with an absorption band peak of 1381.03 $-833.25 \mathrm{~cm}^{-1}$ indicates the vibration of the $\mathrm{C}-\mathrm{O}$ group of $\mathrm{C}-\mathrm{OH}$ which is an impurity. The wave number with an absorption band peak of $756.1 \mathrm{~cm}-1-486.06 \mathrm{~cm}^{-1}$ indicates the presence of aromatic $\mathrm{C}$-H group vibrations which indicate the presence of hydrocarbon compounds.

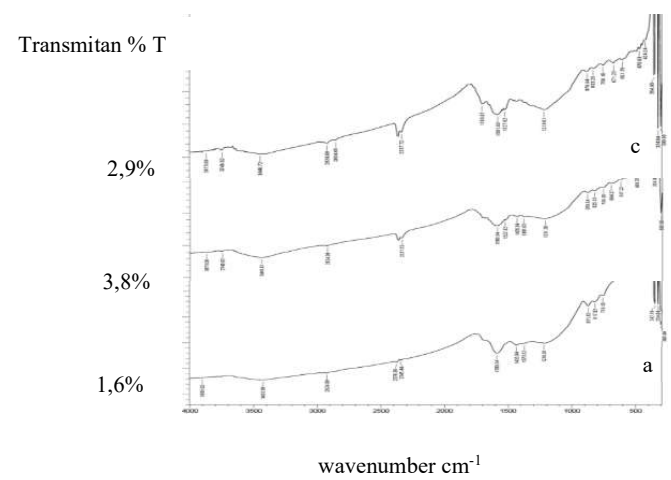

Fig. 6. FTIR Spectrum (a) Basic material charcoal, (b) 1 $\mathrm{M} \mathrm{HNO} 3$ activated charcoal, and (c) $2 \mathrm{M} \mathrm{HNO} 3$ activated charcoal

Spectrum of Fourier Transform Infrared Charcoal Purified with Hot Water (H2O)

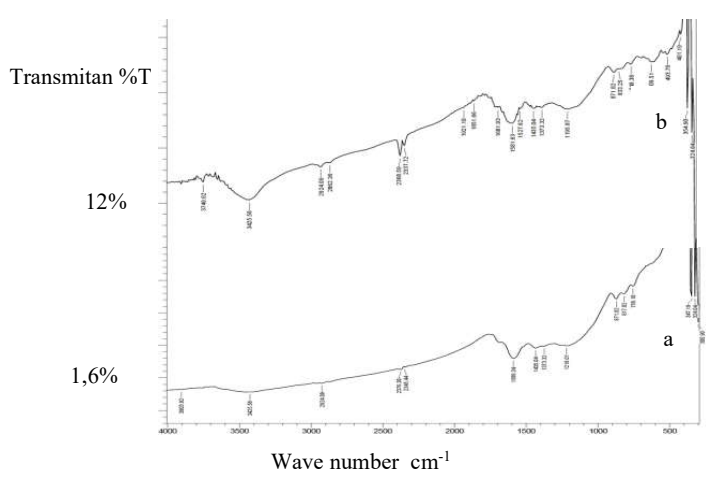

Fig. 7. FTIR Spectrum Image (a) Basic material charcoal (b) Hot water activated charcoal

\section{Discussion}

The FTIR spectrum pattern of activated charcoal using hydrochloric acid, acetic acid, nitric acid and hot water shows that the solvent with a low absorption intensity, namely $2 \mathrm{M}$ hydrochloric acid, indicates that coconut shell charcoal has a high level of purity. 


\section{References}

1. M. J. Rampe., B. Setiaj., W. Trisunaryanti, W. dan Triyono, Fabrication and Characterization of Carbon Composite from Coconut Shell Carbon, Indo.J.Chem., vol. 11, no. 2, p. 124-130, (2011).

2. M. J. Rampe, and S. Lumingkewas, Pore Structure and Specific Surface Area of the Carbon Electrodes from Coconut Shell Charcoal Sintering up to Temperature of $1500 \mathrm{C}$, Inter. Journal of Chem Tech Research, vol. 10, no. 7, p.800-807, (2017).

3. M. J. Rampe and V. A. Tiwow. Synthesis and Characterization of Bio-Coke from Charcoal Coconut Shell, Intern. Journal of ChemTech Research, vol. 10, no.15, p. 312-317, (2017).

4. M. J. Rampe and V. A. Tiwow, Fabrication and Characterization of Activated Carbon from Charcoal Shell Minahasa, Indonesia, IOP Conf. Seris: Journal of Physics. Conf. S 